\title{
Routing Protocol berbasis web pada Cisco Router 2800 series memanfaatkan Application Programming Interface (Api) dari Cisco
}

\author{
Sudaryanto*, Haruno Sajati, Ega Ari Wiyasa \\ Informatic Departement Sekolah Tinggi Teknologi Adisutjipto \\ Email Korespondensi: *sudaryanto@stta.ac.id
}

\begin{abstract}
Abstrak. Routing Protocol merupakan salah satu teknologi komputer yang saat ini sangat dibutuhkan. Hal ini dikarenakan routing dapat digunakan untuk membroadcast, mempelajari jaringan yang saling terhubung dan rute (network path) yang tersedia, serta router yang berbeda bisa saling bertukar informasi untuk mendapat rute paling efisien ke tujuan. Cisco Router merupakan perangkat router yang sudah menyediakan teknologi routing. Permasalahan yang ditemukan pada Cisco Router adalah sistem manajemen routing yang masih berbasis command line dan tidak dapat diakses dari jarak jauh. Pada penelitian ini akan membangun user interface berbasis web untuk Routing Protocol dengan tujuan memberikan kebebasan pemakaian device dan tidak harus terfokus pada satu jenis device saja. Routing berbasis Web ini dibuat dengan memanfaatkan API Cisco sebagai penghubung antara bahasa pemrograman berbasis Web dengan bahasa pada perangkat lunak Cisco Catalyst 2800 dan pemanfaatan Telnet yang berperan penting dalam memberikan akses lebih luas pada Cisco Catalyst 2800 untuk diakses di luar aplikasi terminal emulator. Hasil pengujian pada penelitian ini menunjukkan bahwa Routing Protocol berbasis Web terbukti dapat melakukan konfigurasi routing sehingga dapat digunakan untuk mengatur hubungan antar komputer sesuai dengan kebutuhan pada jaringan yang digunakan.
\end{abstract}

Kata kunci: Routiong Protocol, API Cisco, Telnet, Cisco Router Type 2800 Series.

\section{Pendahuluan}

Saat ini hampir seluruh kebutuhan manusia dapat didukung oleh perkembangan teknologi. Seiring dengan perkembangan jaman, teknologi berkembang dengan sangat pesat. Hal ini dapat dibuktikan dengan kehidupan masyarakat yang sudah mulai meninggalkan kegiatan secara konvensional. Salah satu yang berkembang pesat yaitu teknologi jaringan komputer. Berbagai perusahaan dan instansi sudah mulai menggunakan jaringan komputer guna mengikuti arus perkembangan teknologi yang tidak dapat dihindari. Penyebab pentingnya jaringan komputer adalah kebutuhan akan informasi yang begitu cepat.

Bagian jaringan komputer yang saat ini sangat diperlukan adalah Routing Protocol. Teknik Routing Protocol [1] ini digunakan untuk mem-broadcast, mempelajari jaringan yang saling terhubung dan rute (network path) yang tersedia serta router yang berbeda bisa saling bertukar informasi untuk mendapatkan rute paling efisien ke tujuan. Hal ini bertujuan diantaranya mengatasi broadcast domain, keamanan, peningkatan performa. Router dinamis mampu menentukan jalur yang terbaik dalam menentukan 
pengiriman terbaik untuk sampai tujuan [2]. Router yang terhubung akan saling memberikan informasi dan secara bersama akan membuat tabel routing secara otomatis.

Pada penelitian [3][4] telah berhasil dibuat perangkat lunak berbasis Graphics User Interface (GUI) yang mampu melakukan konfigurasi Virtual Local Area Network (VLAN) dan monitoring interface FastEthernet, akan tetapi aplikasi berbasis Graphics User Interface (GUI) hanya dapat digunakan pada Cisco Switch Catalyst 3750.

Dalam melakukan manajemen keamanan jaringan pada port-port yang tersedia pada switch yaitu : default / static port security, port security dynamic learning, sticky port security [5], dan juga monitoring jaringan dengan menggunakan SNMP [6][7], mikrotik [8], sms [9] dan menggunakan web [10] dimana monitoring jaringan mengunakan piranti mikrotik dengan api-mikrotik sudah dilakukan beberapa peneliti dan belum ada penelitian yang memanage dan memonitoring jaringan dengan menggunakan piranti cisco. Cisco Router merupakan salah satu router yang diproduksi oleh Cisco. Konfigurasi Routing Protocol pada Cisco Router 2800 masih berbasis Command Line, sehingga menuntut administrator jaringan untuk memahami secara keseluruhan perintah-perintah dari konfigurasi Routing Protocol. Tentunya tidak mudah dan tidak efisien. Untuk itu dibutuhkan suatu perangkat lunak berbasis Graphics User Interface (GUI) yang di dalamnya terdapat perintah-perintah dari konfigurasi Routing Protocol. Perangkat lunak tersebut yang akan mempermudah administrator dalam melakukan konfigurasi Routing Protocol. Bagaimana manajemen dan monitoring router dalam jaringan komputer yang digunakan untuk membroadcast dan mempelajari jaringan yang terhubung serta mempelajari rute (network path) yang tersedia dengan melibatkan perangkat lunak berbasis Graphics User Interface (GUI) yang di dalamnya terdapat perintah-perintah dari konfigurasi Routing Protocol. Pada penelitian ini membahas tentang bagaimana membuat routing protocol berbasis web untuk melakukan konfigurasi dynamic routing dan static routing pada cisco router 2800 series dari berbagai device tanpa harus menyentuh router dengan menggunakan perangkat lunak Application Programming Interface (API) dari Cisco.

\section{Metodologi Penelitian}

Metodologi penelitian yang digunakan dalam penelitian ini adalah:

2.1. Pengumpulan Data

1. Observasi

Pada metode ini dilakukan pengamatan secara langsung di laboratorium suatu instansi mengenai hal-hal yang berhubungan dengan manajemen Routing Protocol.

2. Wawancara

Data diperoleh dari beberapa proses, yaitu wawancara dengan pengurus (administrator) laboratorium serta wawancara dengan dosen yang berkompeten di bidangnya.

3. Studi Literatur

Bertujuan untuk mempelajari teori-teori dengan membaca beberapa buku dan jurnal yang berhubungan dengan permasalahan yang dibahas. Khususnya kajian mengenai Routing Protocol.

\subsection{Perancangan Sistem}

Pada Gambar 1 sampai Gambar 3 menjelaskan alur dari dalam sistem. Gambar 1 menjelaskan setelah user berhasil melakukan login, maka user dapat menggunakan menu konfigurasi seperti interface, RIP, Static, Save dan Logout. Gambar 2 menjelaskan setelah user berhasil login maka user dapat menggunakan menu delete, save dan logout. Gambar 3 menjelaskan setelah user berhasil login maka user dapat menggunakan menu report, save dan logout pada aplikasi. Pada menu interface berfungsi untuk memberikan IP pada port router. Pada Bagian RIP dapat digunakan untuk melakukan konfigurasi RIP pada sebuah router. Pada bagian static digunakan untuk memberikan static routing pada sebuah router. Pada bagian Report terdapat submenu yang berisi Show IP, Show Routing RIP, Show Routing Static yang berfungsi untuk menampilkan IP pada port dan juga hasil routing. Sedangkan pada menu delete terdapat submenu yang 
terdiri dari Delete IP, Delete RIP dan Delete Static yang berfungsi untuk menghapus IP dan konfigurasi. Pada menu save berfungsi untuk menyimpan konfigurasi yang sudah dilakukan sebelumnya, hal ini bertujuan agar konfigurasi tidak hilang pada saat router melakukan restart. Sedangkan pada menu logout berfungsi untuk keluar dari aplikasi dengan menghapus username dan password yang sudah pernah dilakukan sebelumnya. Hal ini bertujuan agar pengguna lain tidak dapat menggunakan aplikasi sebelum melakukan login.

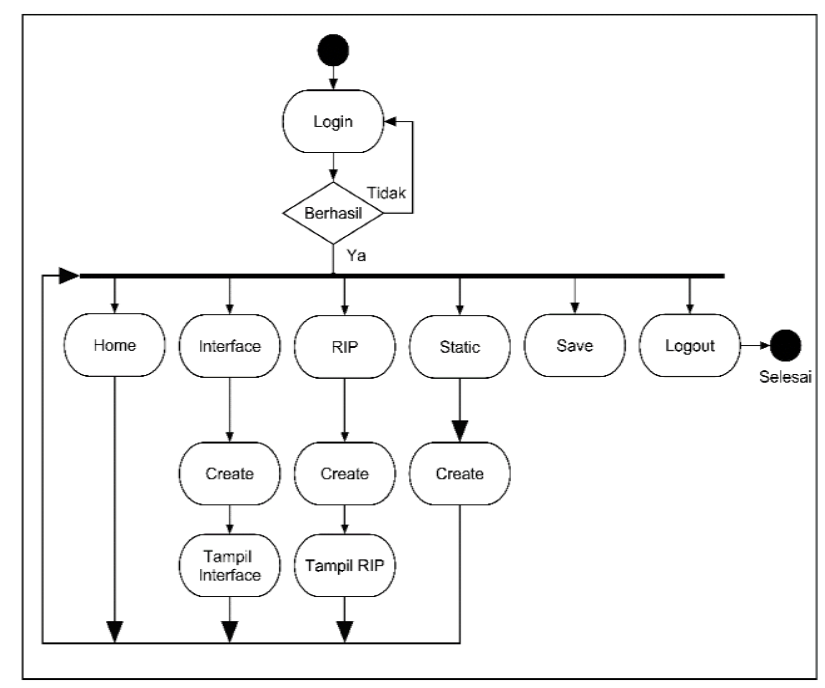

Gambar 1. Activity Diagram Konfigurasi

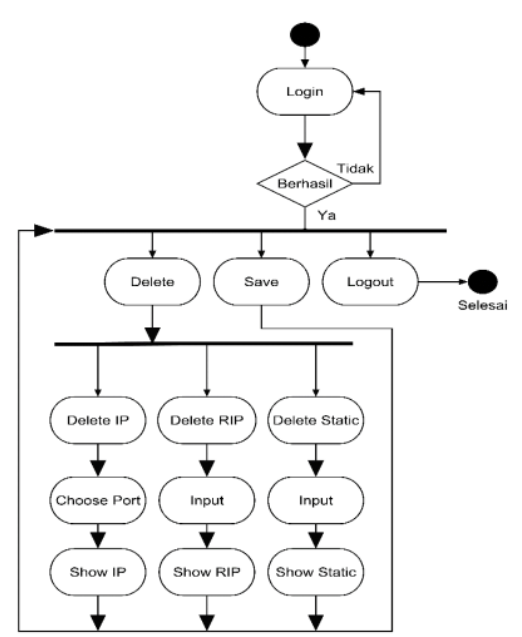

Gambar 2. Activity Diagram Delete 


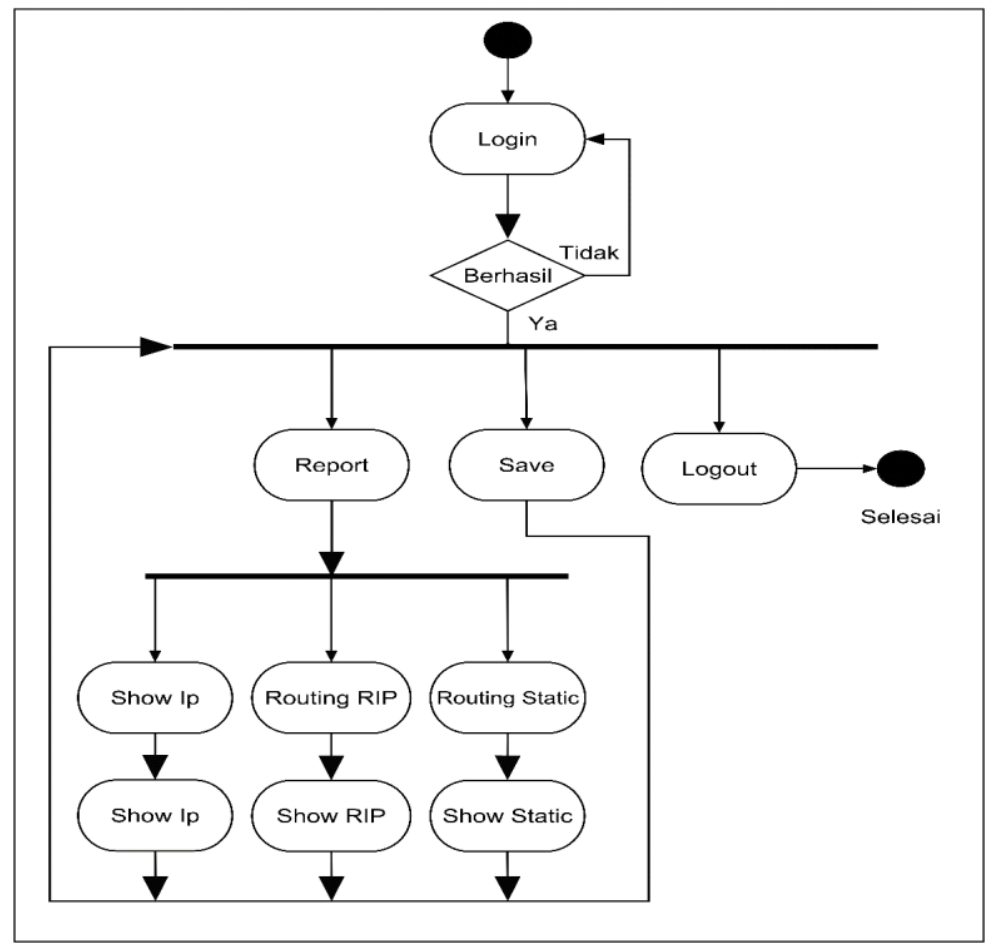

Gambar 3. Activity Diagram Show

2.3. Implementasi dan Uji Coba

Pada tahapan metode ini dilakukan implementasi serta uji coba aplikasi yang dibuat. Implementasi dan uji coba dilakukan pada perangkat Cisco Router dengan design jarring seperti ditunjukan pada Gambar 4.

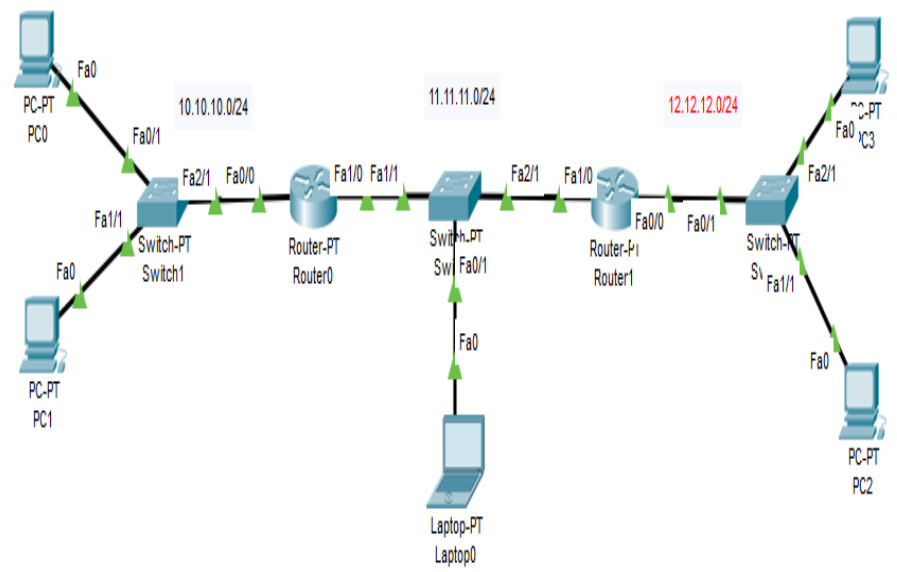

Gambar 4. Design Jaringan 


\section{Hasil dan Pembahasan}

Hasil perancangan atau implementasi VLAN berbasis Web dengan screenshoot tiap menu yang ada dapat dilihat pada Tabel 1.

Tabel 1. Implementasi Static dan Dynamic Routing

\begin{tabular}{|c|c|c|}
\hline $\mathrm{NO}$ & Aktivitas & CLI \\
\hline 1 & $\begin{array}{l}\text { Koneksi } \\
\text { Router }\end{array}$ & 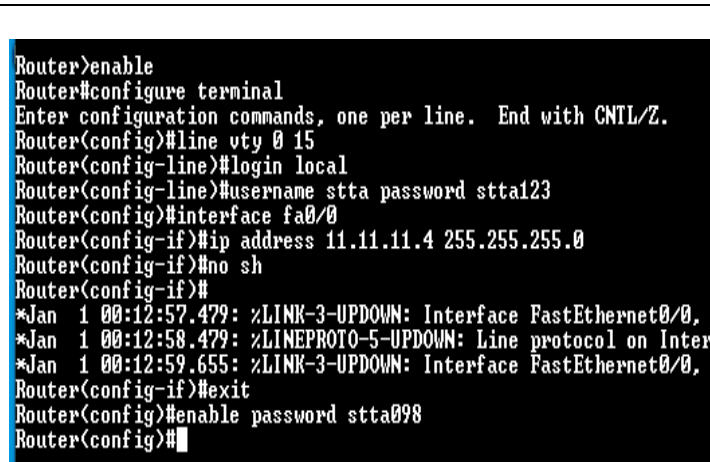 \\
\hline
\end{tabular}

\section{GUI}

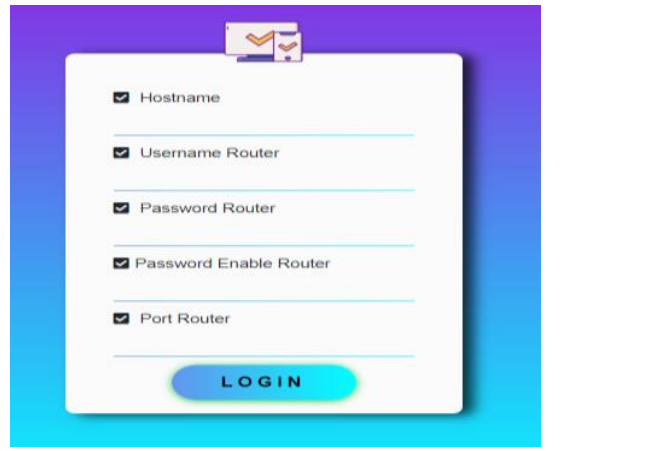

2 Konfigurasi

Interface

Router>en

Router\#configure terminal

Enter configuration cormands, one per line. Ind with CNTL/2.

Router (config) $\#$ interface $\mathrm{F} 0 / 1$

Router(config-if) \#ip address 10.10.10.66 255.255.255.0

Router(config-if) \#no shutdown

Router (config-if) \#

8LINK-5-CHANGBD: Interface FastBthernet0/1, changed state to up |

3 Konfigurasi

Static

Routing

Router>en

Router\&configure terminal

Enter configuration commands, one per line. Ind with CNis/2. Router (config) \#ip route 12.12 .12 .0255 .255 .255 .011 .11 .11 .4 Router (config) $)$

4 Konfigurasi Dynamic

Router>en

Routing

Router\#configure terminal

Enter configuration commands, one per line. End with CNTL/2.

(RIP)
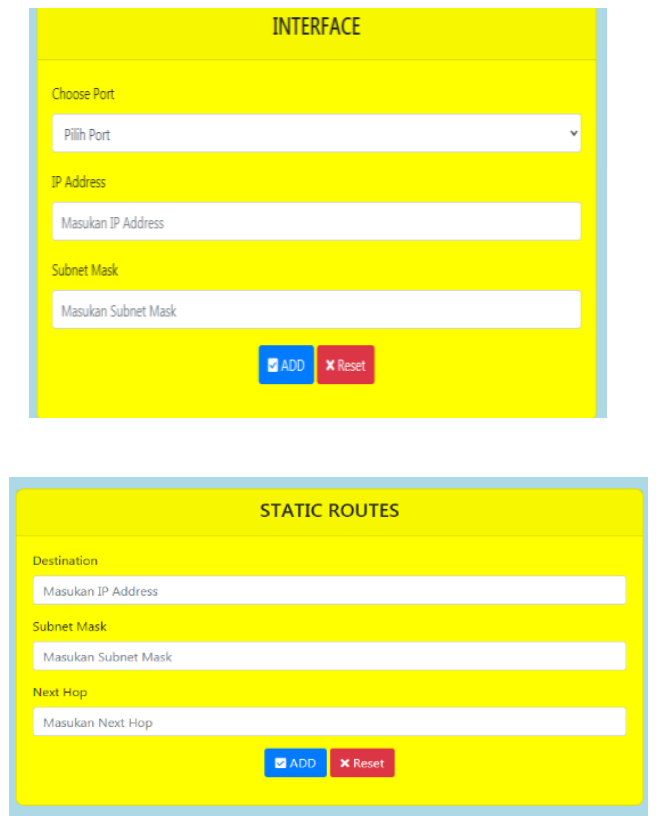

Router (config-router) \#network $10 \cdot 10 \cdot 10.0$

Router (config-router) \#network 11.11.11.0

Router (confiq-router) \#)

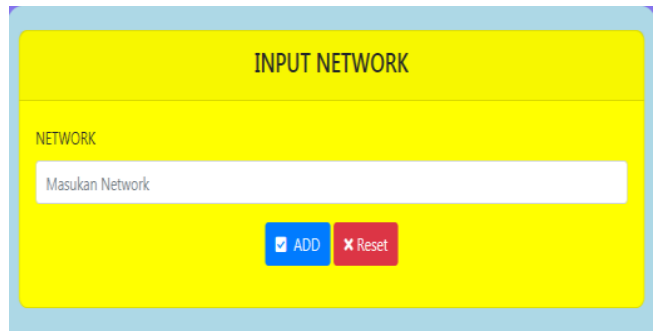



5 Show ip Interface

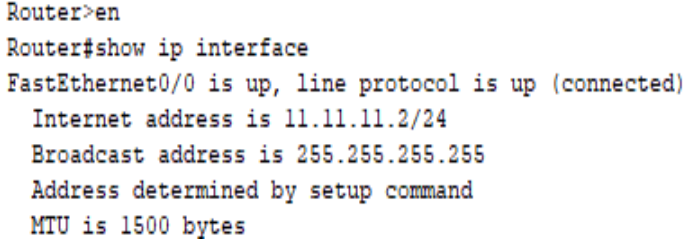

6 Show static routing

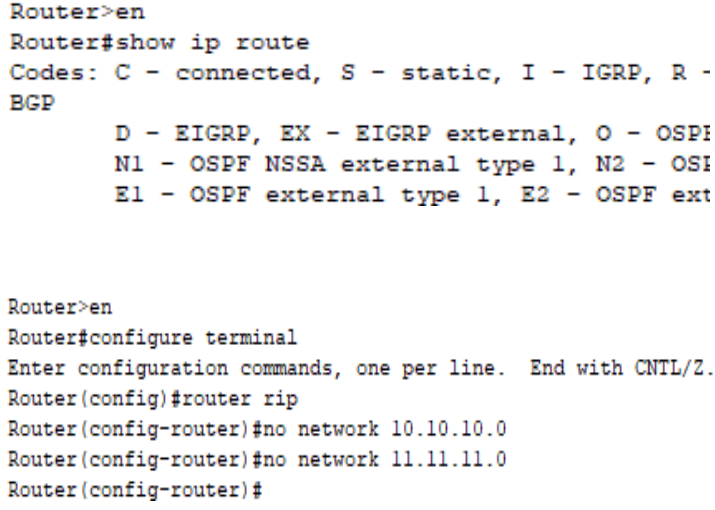

Router>en

Router\#configure terminal

Enter configuration commands, one per line. End with CNIL/2.

Router (config) \#router rip

Router (config-router) \#no network $10 \cdot 10.10$.

Router (config-router) \#no network 11.11 .11 .

Router (config-router) \#

7 Delete

Dynamic

Routing

(RIP)

\begin{tabular}{|c|}
\hline IP ROUTE \\
\hline 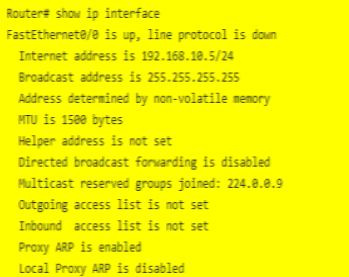 \\
\hline
\end{tabular}

\section{CONFIGURATION STATIC}

Fouter: show ip roste static

pouters

\subsection{Pengujian}

Pada Gambar 5 merupakan personal computer yang akan melakukan tes ping.

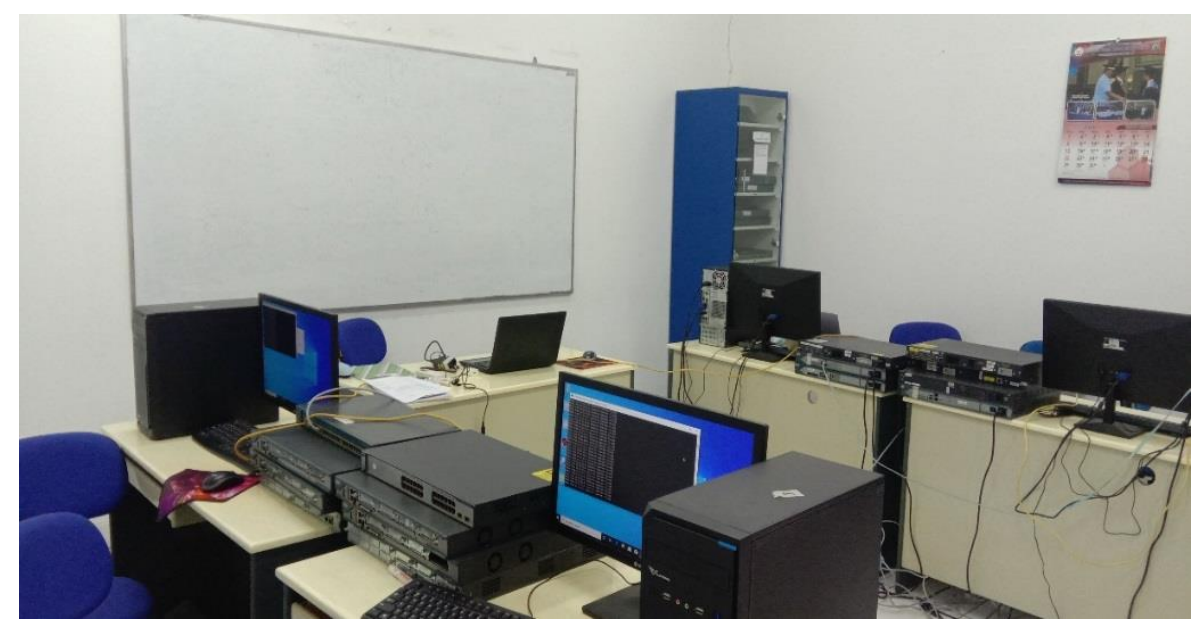

Gambar 5. 1 Personal Computer

Pada Gambar 4 dapat dijelaskan mengenai port yang terhubung pada setiap personal computer dengan router serta penjelasan IP pada setiap unit yang ada. Hal ini dapat mempermudah dalam pengujian agar admin/user tidak lupa pada IP yang sudah diberikan untuk setiap device. Pada Gambar 4 dapat dilihat alur atau scheme yang akan dilakukan dalam pengujian aplikasi berbasis web. Tabel IP dapat dilihat pada Tabel 2. 
Routing protocol berbasis web pada Cisco Router 2800 series memanfaatkan Application Programming.....

Tabel 2. IP Address

\begin{tabular}{cccccc}
\hline NO & \multirow{2}{*}{ NAMA } & $\begin{array}{c}\text { IP } \\
\text { ADDRESS }\end{array}$ & $\begin{array}{c}\text { SUBNET } \\
\text { MASK }\end{array}$ & INTERFACE & INPUT \\
\hline 1 & PC0 & 10.10 .10 .4 & 255.255 .255 .0 & FastEthernet 0/1 & Router-0 \\
2 & PC1 & 10.10 .10 .6 & 255.255 .255 .0 & FastEthernet 0/1 & Router-0 \\
3 & PC2 & 12.12 .12 .4 & 255.255 .255 .0 & FastEthernet 0/1 & Router-1 \\
4 & PC3 & 12.12 .12 .6 & 255.255 .255 .0 & FastEthernet 0/1 & Router-1 \\
5 & LAPTOP & 11.11 .11 .6 & 255.255 .255 .0 & FastEthernet 0/0 & Router-0, \\
& & & & & Router-1 \\
6 & Router-0 & 10.10 .10 .66 & 255.255 .255 .0 & FastEthernet 0/1 & - \\
7 & Router-0 & 11.11 .11 .2 & 255.255 .255 .0 & FastEthernet 0/0 & - \\
8 & Router-1 & 11.11 .11 .4 & 255.255 .255 .0 & FastEthernet 0/0 & - \\
9 & Router-1 & 12.12 .12 .2 & 255.255 .255 .0 & FastEthernet 0/1 & - \\
\hline
\end{tabular}

\section{Pengujian Tanpa Routing}

Pada tahap ini, seluruh personal computer yang terhubung dengan router tidak menggunakan static routing ataupun dynamic routing. Tes ping dilakukan pada setiap personal computer. Tes ping tanpa routing dapat dilihat pada Tabel 3 .

Tabel 3. Tes Ping Tanpa Routing

\begin{tabular}{cccccc}
\hline NO & NAMA & IP TUJUAN & NAMA TUJUAN & INTERFACE & HASIL \\
\hline 1 & PC1 & 10.10 .10 .66 & Router-0 & FastEthernet 0/1 & Berhasil \\
2 & PC1 & 11.11 .11 .2 & Router-0 & FastEthernet 0/0 & Berhasil \\
3 & PC1 & 11.11 .11 .4 & Router-1 & FastEthernet 0/0 & Tidak Berhasil \\
4 & PC1 & 12.12 .12 .2 & Router-1 & FastEthernet 0/1 & Tidak Berhasil \\
5 & PC1 & 10.10 .10 .4 & PC2 & FastEthernet 0/0 & Berhasil \\
6 & PC1 & 12.12 .12 .4 & PC3 & FastEthernet 0/0 & Tidak Berhasil \\
7 & PC1 & 12.12 .12 .6 & PC4 & FastEthernet 0/0 & Tidak Berhasil \\
8 & PC2 & 10.10 .10 .66 & Router-0 & FastEthernet 0/1 & Berhasil \\
9 & PC2 & 11.11 .11 .2 & Router-0 & FastEthernet 0/0 & Berhasil \\
10 & PC2 & 11.11 .11 .4 & Router-1 & FastEthernet 0/0 & Tidak Berhasil \\
11 & PC2 & 12.12 .12 .2 & Router-1 & FastEthernet 0/1 & Tidak Berhasil \\
12 & PC2 & 10.10 .10 .6 & PC1 & FastEthernet 0/0 & Berhasil \\
13 & PC2 & 12.12 .12 .4 & PC3 & FastEthernet 0/0 & Tidak Berhasil \\
14 & PC2 & 12.12 .12 .6 & PC4 & FastEthernet 0/0 & Tidak Berhasil \\
15 & PC3 & 10.10 .10 .66 & Router-0 & FastEthernet 0/1 & Tidak Berhasil \\
\hline
\end{tabular}

2. Pengujian dengan Static Routing

Pada tahap ini, aplikasi berbasis web digunakan untuk melakukan pengujian static routing. Konfigurasi static routing akan dilakukan pada setiap router dengan menggunakan aplikasi berbasis web. User dapat menggunakan form static untuk melakukan konfigurasi static routing. User perlu mengisi kolom input pada form static yang sudah disediakan. User hanya memerlukan Destination, subnet mask dan next-hop. Setelah konfigurasi selesai, dilakukan pengujian dengan cara tes ping ada setiap personal computer.

Pada Tabel 4 dapat dijelaskan koneksi setiap personal computer dengan router. Pada tahap ini, konfigurasi router dengan menggunakan static routing. Pengujian dilakukan dengan menggunakan aplikasi berbasis web. Dapat disimpulkan dengan "HASIL" bahwa konfigurasi static routing dapat berjalan sesuai dengan fungsinya. 
Tabel 4. Tes Ping Static

\begin{tabular}{cccccc}
\hline NO & NAMA & IP TUJUAN & \multirow{2}{*}{ NAMA TUJUAN } & INTERFACE & HASIL \\
\hline 1 & PC1 & 10.10 .10 .66 & Router-0 & FastEthernet 0/1 & Berhasil \\
2 & PC1 & 11.11 .11 .2 & Router-0 & FastEthernet 0/0 & Berhasil \\
3 & PC1 & 11.11 .11 .4 & Router-1 & FastEthernet 0/0 & Berhasil \\
4 & PC1 & 12.12 .12 .2 & Router-1 & FastEthernet 0/1 & Berhasil \\
5 & PC1 & 10.10 .10 .4 & PC2 & FastEthernet 0/0 & Berhasil \\
6 & PC1 & 12.12 .12 .4 & PC3 & FastEthernet 0/0 & Berhasil \\
7 & PC1 & 12.12 .12 .6 & PC4 & FastEthernet 0/0 & Berhasil \\
8 & PC2 & 10.10 .10 .66 & Router-0 & FastEthernet 0/1 & Berhasil \\
9 & PC2 & 11.11 .11 .2 & Router-0 & FastEthernet 0/0 & Berhasil \\
10 & PC2 & 11.11 .11 .4 & Router-1 & FastEthernet 0/0 & Berhasil \\
11 & PC2 & 12.12 .12 .2 & Router-1 & FastEthernet 0/1 & Berhasil \\
12 & PC2 & 10.10 .10 .6 & PC1 & FastEthernet 0/0 & Berhasil \\
13 & PC2 & 12.12 .12 .4 & PC3 & FastEthernet 0/0 & Berhasil \\
14 & PC2 & 12.12 .12 .6 & PC4 & FastEthernet 0/0 & Berhasil \\
15 & PC3 & 10.10 .10 .66 & Router-0 & FastEthernet 0/1 & Berhasil \\
\hline
\end{tabular}

Pada Tabel 4 membuktikan bahwa konfigurasi secara Static routing dengan menggunakan Graphical User Interface (GUI) dan command line memiliki hasil yang sama.

3. Pengujian dengan Dynamic Routing

Pada tahap ini, konfigurasi router dengan menggunakan Routing Information Protocol. Aplikasi berbasis web akan melakukan proses konfigurasi pada router-0 dan router-1. Admin perlu memasukan network pada setiap router dengan menggunakan fasilitas yang ada pada form RIP.

Tes ping dilakukan pada setiap personal computer, hal ini berfungsi untuk memastikan bahwa personal computer sudah terhubung. Setiap personal computer akan mencoba tes ping dengan jaringan yang berbeda.

Pada Tabel 5 dapat dijelaskan koneksi setiap personal computer dengan router. Pada tahap ini, dapat dibuktikan bahwa dynamic routing dengan menggunakan aplikasi berbasis web dapat berjalan sesuai dengan perancangan.

Tabel 5. Tes Ping RIP

\begin{tabular}{cccclc}
\hline NO & NAMA & IP TUJUAN & NAMA TUJUAN & INTERFACE & HASIL \\
\hline 1 & PC1 & 10.10 .10 .66 & Router-0 & FastEthernet 0/1 & Berhasil \\
2 & PC1 & 11.11 .11 .2 & Router-0 & FastEthernet 0/0 & Berhasil \\
3 & PC1 & 11.11 .11 .4 & Router-1 & FastEthernet 0/0 & Berhasil \\
4 & PC1 & 12.12 .12 .2 & Router-1 & FastEthernet 0/1 & Berhasil \\
5 & PC1 & 10.10 .10 .4 & PC2 & FastEthernet 0/0 & Berhasil \\
6 & PC1 & 12.12 .12 .4 & PC3 & FastEthernet 0/0 & Berhasil \\
7 & PC1 & 12.12 .12 .6 & PC4 & FastEthernet 0/0 & Berhasil \\
8 & PC2 & 10.10 .10 .66 & Router-0 & FastEthernet 0/1 & Berhasil \\
9 & PC2 & 11.11 .11 .2 & Router-0 & FastEthernet 0/0 & Berhasil \\
10 & PC2 & 11.11 .11 .4 & Router-1 & FastEthernet 0/0 & Berhasil \\
11 & PC2 & 12.12 .12 .2 & Router-1 & FastEthernet 0/1 & Berhasil \\
12 & PC2 & 10.10 .10 .6 & PC1 & FastEthernet 0/0 & Berhasil \\
13 & PC2 & 12.12 .12 .4 & PC3 & FastEthernet 0/0 & Berhasil \\
14 & PC2 & 12.12 .12 .6 & PC4 & FastEthernet 0/0 & Berhasil \\
15 & PC3 & 10.10 .10 .66 & Router-0 & FastEthernet 0/1 & Berhasil \\
\hline
\end{tabular}


Pada Tabel 5 membuktikan bahwa konfigurasi secara dynamic routing dengan menggunakan Graphical User Interface (GUI) dan command line memiliki hasil yang sama.

4. Pengujian Efisiensi CLI dengan GUI

Pada tahap ini, pengujian dilakukan untuk mengetahui perbandingan (kecepatan) antara konfigurasi menggunakan CLI dengan GUI. Pengujian pada setiap konfigurasi dilakukan sebanyak lima kali percobaan tanpa kesalahan.

Tabel 6. Pengujian CLI Dan GUI

\begin{tabular}{cccc}
\hline No & Configuration & $\begin{array}{c}\text { Avarage } \\
\text { CLI }\end{array}$ & $\begin{array}{c}\text { Avarage } \\
\text { GUI }\end{array}$ \\
\hline 1 & SAVE & 17.6 & 2.8 \\
2 & INPUT IP & 41.4 & 10.6 \\
3 & STATIC ROUTING & 66.8 & 11.2 \\
4 & DYNAMIC ROUTING & 69.2 & 12.4 \\
5 & SHOW IP & 9.6 & 0.86 \\
6 & SHOW RIP & 10.2 & 0.71 \\
7 & SHOW STATIC & 9.8 & 0.7 \\
8 & DELETE IP & 4.1 & 3.8 \\
9 & DELETE RIP & 44 & 2.8 \\
10 & DELETE STATIC & 39.8 & 10.8 \\
\hline
\end{tabular}

Hasil dari percobaan diambil nilai average sebagai perbandingan antara CLI dengan GUI. Pengujian CLI dan GUI dapat dilihat pada Tabel 6. Berdasarkan hasil pengujian, GUI dengan rata-rata 5.667 dan CLI mempunyai rata-rata 31.25 sehingga bila diakumulasi GUI lebih cepat dibandingkan dengan menggunakan CLI.

\section{Kesimpulan}

1. Konfigurasi static routing dan dynamic routing dapat dilakukan dengan aplikasi berbasis web yang dihubungkan melalui API pada Cisco Router type 2800 series. Sehingga tidak diperlukan command line untuk melakukan konfigurasi static routing dan dynamic routing.

2. Konfigurasi static routing dan dynamic routing dapat dilakukan dari jarak jauh (online) dengan syarat ketersediaan jaringan internet dan web browser, ataupun jarak dekat (offline).

3. Aplikasi berbasis web ini terbukti dapat digunakan untuk membuat static routing ataupun dynamic routing dengan bermacam device mempunyai browser.

4. Aplikasi yang dibangun hanya bisa digunakan untuk Routing protocols.

5. Berdasarkan nilai pengujian Graphics User Interface (GUI) dibandingan dengan menggunakan command line. Graphics User Interface (GUI) memiliki keunggulan dalam hal kecepatan, ketepatan dan dapat mempermudah administrator.

\section{Ucapan Terima Kasih}

Penulis mengucapkan terima kasih kepada Sekolah Tinggi Teknologi Adisutjipto Yogyakarta yang telah memberi dukungan finansial terhadap penelitian ini. Juga kepada bagian P3M STTA yang telah membantu tugas dosen untuk melaksanakan salah satu Tridharma perguruan tinggi. 


\section{Daftar Pustaka}

[1] Mahmood A.N. (2020). Performance Analysis of Routing Protocols RIP,EIGRP,OSPF,IGRP using Networks connecter. EasyChair.

[2] Miftah, Z. (2016). Analisis Peningkatan Kinerja LAN Dengan Routing Dinamis Berbasis OSPF Single Area Dan InterVLAN Menggunakan Cisco Packet Tracer 7.1, 9.

[3] Ayuningtyas, A., Sudaryanto, \& Cessara, D. D. (2020). Sistem Manajemen Virtual Local Area Network (VLAN) Pada Cisco Catalyst 3750 Berbasis Web. In Simetris, 11.

[4] Sudaryanto, \& Nurhayati, D. (2019). Monitoring Interfaces FastEthernet On Cisco Catalyst 3750 To Ensure Use Of The Security Computer Network In STTA Computing Laboratories. In Conference SENATIK STT Adisutjipto Yogyakarta, 5.

[5] Sulaiman, K. (2016). Analisis Sistem Keamanan Jaringan Dengan Menggunakan Switch Port Security. CESS (Journal Of Computer Engineering, System And Science) (Vol. 1, ISSN :25027131)

[6] Rinaldo, R. (2016). Implementasi Sistem Monitoring Jaringan Menggunakan Microtik Router Os Di Universitas Islam Batik Surakarta. Jurnal Emitor, 16(2), 5-12.

[7] Gobel. M. A. A., Sumarsono. S., \& Indrianingsih. Y. (2012). Notification Of Security Threats On The Internet Proxy Server Is A Server-Based Short Message Service (Sms). In Compiler STT Adisutjipto Yogyakarta, 1(1), 77-90.

[8] Pradikta, R., Affandi, A., \& Setijadi, E. (2013). Rancang Bangun Aplikasi Monitoring Jaringan Dengan Menggunakan Simple Network Management Protocol. Jurnal Teknik Pomits, 2(1), 154159.

[9] Herliana, A., Rasyid, P.M. (2016). Sistem Informasi Monitoring Pengembangan Software Pada Tahap Development Berbasis Web. Jurnal Informatika, 3(1), 41-50.

[10] Taftazanie, S., Prasetijo, A. B., \& Widianto, E. D. (2017). Aplikasi Pemantau Perangkat Jaringan Berbasis Web Menggunakan Protokol SNMP Dan Notifikasi Sms. Jurnal Teknologi dan Sistem Komputer, 5(2), 62-68. 